"Mircea cel Batran" Naval Academy Scientific Bulletin, Volume XIX - 2016 - Issue 1

Published by "Mircea cel Batran" Naval Academy Press, Constanta, Romania // The journal is indexed in:

PROQUEST / DOAJ / DRJI / JOURNAL INDEX / I2OR / SCIENCE LIBRARY INDEX / Google Scholar / Crossref /

Academic Keys I ROAD Open Access / OAJI / Academic Resources / Scientific Indexing Services / SCIPIO

\title{
AUTONOMOUS AERIAL SURVEILLANCE SYSTEM MOVEMENT MONITORING BY USING STRAP-DOWN INERTIAL TECHNIQUES
}

\author{
Nicolae JULA ${ }^{1}$ \\ Alexandru SOFRONIA ${ }^{1}$ \\ Teodor Lucian GRIGORIE ${ }^{1}$ \\ ${ }^{1}$ INSOFT Development \& Consulting, Bucharest, Romania
}

\begin{abstract}
The paper presents an inertial navigation algorithm used for an Unmanned Aerial Vehicle (UAV) boarding an optical detection system for the detection of the Corona discharge in high voltage power lines. The developed algorithm may be used both on real time positioning, but also in the debriefing process after the flight test, when the inflight acquired acceleration and angular speed data are processed together with the captured video streams, received by the Ground Mission Analysis System (GMAS). The integrated system was developed in a research project aiming the reduction of the losses in the transport of strategic interest utilities by using an advanced monitoring system based on IT\&C infrastructure and autonomous aerial surveillance. In the paper are successively shown: 1) a short description of the research project; 2) the architecture of the strap-down inertial navigator and the associated mathematical model; 3) the software implementation of the navigator for the debriefing process, and 4) some positioning evaluation results based on the developed navigation algorithm.
\end{abstract}

Keywords: autonomous aerial surveillance, flight test data analysis, strap-down inertial navigation, mathematical model, software implementation.

\section{Introduction}

Corona discharge can be defined as an autonomous process occurring around an electrode with a small radius of curvature, when is applied a voltage equal or greater than a critical value, dependent on the geometric characteristics of the electrode and on the environmental conditions. This discharge can produce active power losses on high voltage power lines, electrical radio interference, and the aging of the liquid and solid insulations ([1]). Also, it causes audible noise, purple glow, ozone production, and distress in animals sensitive to the ultraviolet light. Although it is a low energy process, in time, the continuous and cumulative characters of its effects may cause serious problems in electrical power lines, reaching up to the system failure. The most dangerous aspect is that the systems failures can occur without any preliminary warning ([2], [3]).

To limit the effects of this discharge on the electrical power lines, its detection and the removal of the factors that generated it are needed. In this way, various mechanisms to inspect the power lines were proposed and implemented. In a classical way, human crews are sent to inspect the lines on foot or in vehicles, which involves making multiple stops along them, and even people climbing on towers to make a closer inspection. Another technique is based on the trained inspectors who supervise the lines from a helicopter, by using binoculars and special video cameras. Both techniques are expensive, time consuming and require the deep implication and a lot of dangers for human factor. Based on promising benefits of the unmanned aerial systems at the level of costs, automation, surveillance speed and low impact at the human factor level, currently were designed and developed few surveillance systems based on this kind of aerial platforms ([2], [4]). T

In this context, our team performed research activities in a project related to the development of an advanced monitoring system for reducing the losses in the transport of strategic interest utilities, based on IT\&C infrastructure and autonomous aerial surveillance. One research direction of this project was reserved to the detection of the Corona discharge by developing an integrated surveillance system based on an Unmanned Aerial Vehicle (UAV) and on a boarded optical detection system with two CCD (charge coupled device) image sensors used in UV and visible spectrum (Fig. 1). Once the images captured, the data are recorded and transmitted to the ground. Simultaneously, the UAV transmits to the ground the telemetry data related to the flight monitoring. All of these data are received by a Ground Control Station (GCS) and real time transmitted to a data processing unit Ground Mission Analysis System (GMAS).

The innovative character of the project comes from implementing solutions of data acquisitions from intelligent sensors and video cameras in visible and UV, from image processing specially designed for each application, from the possibility of detecting flaws on lines and correlating the losses in accordance with the acquired information, from solutions of command of the flight platform with the 
"Mircea cel Batran" Naval Academy Scientific Bulletin, Volume XIX - 2016 - Issue 1

Published by "Mircea cel Batran" Naval Academy Press, Constanta, Romania // The journal is indexed in: PROQUEST / DOAJ / DRJI / JOURNAL INDEX / I2OR / SCIENCE LIBRARY INDEX / Google Scholar / Crossref /

Academic Keys / ROAD Open Access / OAJI / Academic Resources / Scientific Indexing Services / SCIPIO

possibility to automatically return the autonomous air system back to the section where the flaw was detected.

The current paper presents an inertial navigation algorithm used for our aerial system both on real time positioning, but also in the debriefing process after the flight test, when the inflight acquired acceleration and angular speed data are processed together with the instrumentation data.

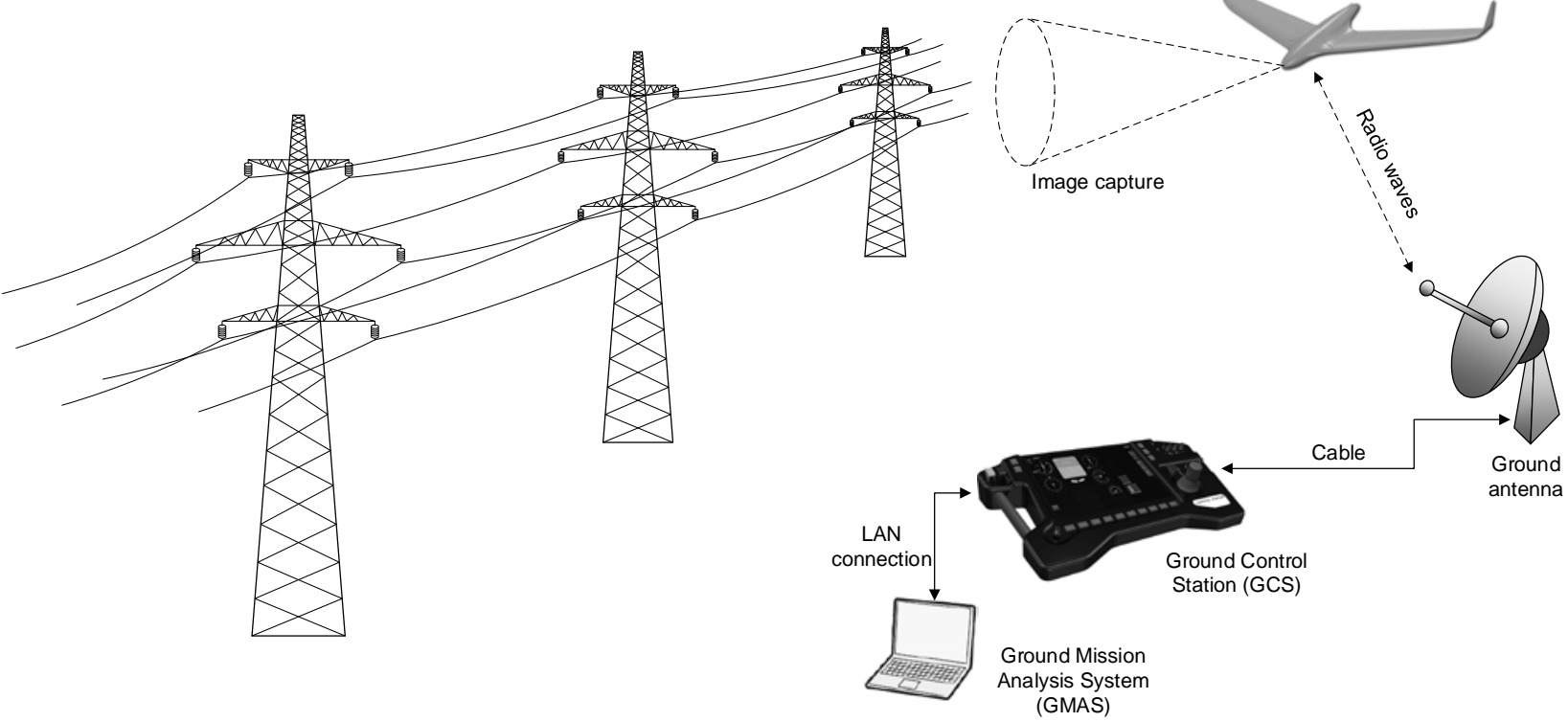

Fig. 1 Integrated aerial surveillance system for the Corona discharge detection in high voltage power lines

The architecture of the strap-down inertial navigator and the associated mathematical model

Firstly used as stand-alone systems, the inertial navigation systems (INSs) play currently an important role near the GPS in high precision integrated navigators used in aerospace applications ([5]-[8]). In time, due to the significant changes at the level of the used technologies for inertial detection but also at the level of the used technologies for data processing systems, these systems known various configurations, more or less accurate, more or less expensive, with classical or unconventional detection units ([9]). The actual trend is to use such systems, in a miniaturized strap-down configuration, with low cost inertial sensors, near a GPS in order to deliver to the user a real time accurate solution of navigation in terms of vehicle position, speed and attitude. In this integrated configuration, beside the positioning and vehicle speed estimation, the main challenge of the INS is to provide the mechanism for the vehicle attitude calculation in terms of yaw, roll and pitch angles ([10]-[12]). The avionics systems, the autopilots, the navigation system and the weapons system, are based on a correct and accurate calculation of these angles. To monitor the vehicle movement in a three-dimensional space by using such inertial techniques, two basic information are needed: the linear acceleration and

DOI: 10.21279/1454-864X-16-I1-040

(c) 2015. This work is licensed under the Creative Commons Attribution-Noncommercial-Share Alike 4.0 License. the angular speed of the vehicle relative to the navigation frame; the used instruments for the acceleration and angular speed detection are accelerometers, and gyros, respectively ([13], [14]).

The following calculation steps need to be performed in this kind of inertial navigators (Fig. 2 [12]): 1) Determination of the vehicle attitude relative to the navigation frame starting from the components of the vehicle angular speed provided by the gyros and from the vehicle initial attitude; 2) Calculation of the acceleration components on the navigation frame axes by transforming the acceleration components, measured by the accelerometers in vehicle frame, using the attitude data; 3) Numerical integration of the acceleration components in navigation frame to determine the vehicle's speed and current position. Having in mind that accelerometers do not differentiate the gravitational acceleration and the kinematic acceleration, a gravitational model of the Earth is required to perform a correction step of the measured acceleration with the gravitational acceleration. 
"Mircea cel Batran" Naval Academy Scientific Bulletin, Volume XIX - 2016 - Issue 1

Published by "Mircea cel Batran" Naval Academy Press, Constanta, Romania // The journal is indexed in:

PROQUEST / DOAJ / DRJI / JOURNAL INDEX / I2OR / SCIENCE LIBRARY INDEX / Google Scholar / Crossref /

Academic Keys I ROAD Open Access / OAJI / Academic Resources / Scientific Indexing Services / SCIPIO

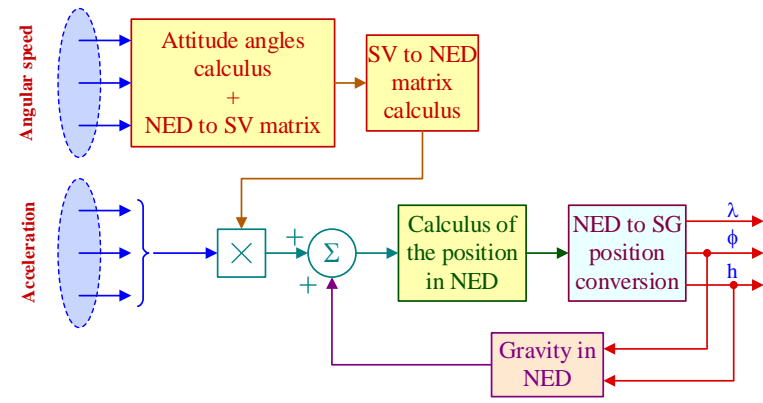

Fig. 2 INS general architecture

\section{Attitude algorithm}

A first step need to be done in the design of an inertial navigator is to clarify the problem of navigation which should be solved. After this preliminary step, the designer should establish the reference frames implied in the evaluation of the solution of navigation provided to the user. Considering the navigation requirements imposed by our aerial systems, our team chosen as needed reference frame the next ones ([7], [12]): 1) EarthCentered-Earth-Fixed (ECEF) frame (OX $\left.{ }^{P} Y^{P} Z^{P}\right) ; 2$ ) Local vertical geodetic (GS) frame $\left(O X^{G} Y^{G} Z^{G}\right) ; 3$ ) Local North-East-Down (NED) frame $\left(O^{\prime} x_{1}, y_{1} z_{l}\right)$ called, also, the navigation frame (NAV-frame); 4) Body frame (SV) $\left(\left(\mathrm{O}_{v} x_{v} y_{v} z_{v}\right)\right.$ (Fig. 3 [12]).

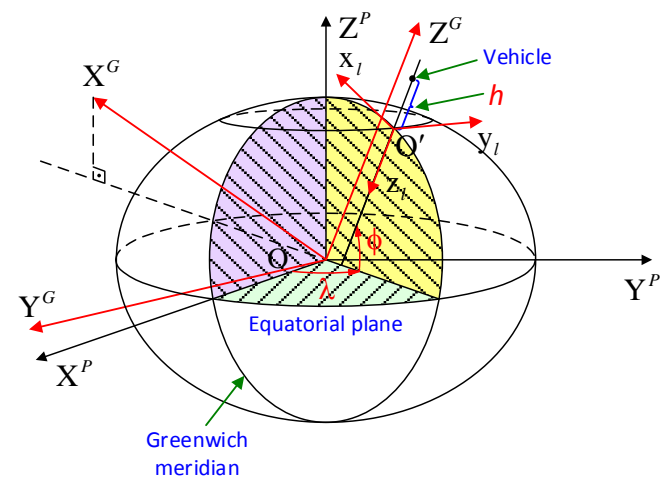

Fig. 3 Reference frames

The vehicle positioning in relation to the reference ellipsoid requires the determination of its geodetic coordinates in terms of longitude, latitude and altitude $(\lambda, \quad$ and $h)$. From our problem of navigation, and having in mind the chosen reference frames, can be considered with enough accuracy that for applications in which it is suitable to use our navigator the rotation speed of the Earth can be neglected and ECEF frame considered as quasi-inertial. Therefore, the components of the vehicle linear acceleration, read from the triad of accelerometers in SV system, should be transformed in NED coordinates and numerically integrated in order to deduct the speed and position. Once determined the spatial coordinates of the vehicle relative to NED frame, will resort to their conversion into geodetic coordinates. Switching between NED and SG is not done directly, but involves an intermediate conversion in ECEF frame ([7], [12], [13]).

For the vehicle attitude determination the literature provides two equivalent parametrizations, quaternionic and matriceal, but at the final both of them estimate the SV to NED transformation matrix $R_{v}^{\prime}$. At each time, the known quantities are the vehicle angular speed components in SV frame, provided by the three gyros in the strapdown inertial measurement unit $\omega_{x}, \omega_{y}, \omega_{z}$. The quaternionic equation to be integrated is ([10], [14])

$$
\dot{Q}=\frac{1}{2}\left[\begin{array}{cccc}
0 & \omega_{z} & -\omega_{y} & \omega_{x} \\
-\omega_{z} & 0 & \omega_{x} & \omega_{y} \\
\omega_{y} & -\omega_{x} & 0 & \omega_{z} \\
-\omega_{x} & -\omega_{y} & -\omega_{z} & 0
\end{array}\right]\left[\begin{array}{c}
q_{1} \\
q_{2} \\
q_{3} \\
q_{0}
\end{array}\right] .
$$

For the integration algorithm a six order Wilcox method was chosen ([12], [15]); the elements of the attitude quaternion $Q$ at the time $t_{n+1}$ result as follows

$$
\left[\begin{array}{c}
q_{1} \\
q_{2} \\
q_{3} \\
q_{0}
\end{array}\right]_{t_{n+1}}=\left[\begin{array}{cccc}
C_{m} & S_{m} \Delta \phi_{z}\left(t_{n}\right) & -S_{m} \Delta \phi_{y}\left(t_{n}\right) & S_{m} \Delta \phi_{x}\left(t_{n}\right) \\
-S_{m} \Delta \phi_{z}\left(t_{n}\right) & C_{m} & S_{m} \Delta \phi_{x}\left(t_{n}\right) & S_{m} \Delta \phi_{y}\left(t_{n}\right) \\
S_{m} \Delta \phi_{y}\left(t_{n}\right) & -S_{m} \Delta \phi_{x}\left(t_{n}\right) & C_{m} & S_{m} \Delta \phi_{z}\left(t_{n}\right) \\
-S_{m} \Delta \phi_{x}\left(t_{n}\right) & -S_{m} \Delta \phi_{y}\left(t_{n}\right) & -S_{m} \Delta \phi_{z}\left(t_{n}\right) & C_{m}
\end{array}\right]\left[\begin{array}{c}
q_{1} \\
q_{2} \\
q_{3} \\
q_{0}
\end{array}\right]_{t_{n}}
$$

$C_{m}, S_{m}$ are the coefficients of the Wilcox method,

$$
\begin{aligned}
& C_{m}=1-\phi_{0}^{2} / 8+\phi_{0}^{4} / 384-\phi_{0}^{6} / 46080 \\
& S_{m}=1 / 2-\phi_{0}^{2} / 48+\phi_{0}^{4} / 3840
\end{aligned}
$$

and $\Delta \phi_{x}, \Delta \phi_{y}, \Delta \phi_{z}$ are the angular increments from the roll, pitch and yaw axes;

$$
\begin{aligned}
& \Delta \phi_{x}\left(t_{n}\right)=\int_{t_{n}}^{t_{n+1}} \omega_{x}\left(t_{n}\right) \mathrm{d} t=\omega_{x}\left(t_{n}\right)\left(t_{n+1}-t_{n}\right)=\omega_{x}\left(t_{n}\right) \Delta t, \\
& \Delta \phi_{y}\left(t_{n}\right)=\int_{t_{n}}^{t_{n}} \omega_{y}\left(t_{n}\right) \mathrm{d} t=\omega_{y}\left(t_{n}\right)\left(t_{n+1}-t_{n}\right)=\omega_{y}\left(t_{n}\right) \Delta t, \\
& \Delta \phi_{z}\left(t_{n}\right)=\int_{t_{n}}^{t_{n+1}} \omega_{z}\left(t_{n}\right) \mathrm{d} t=\omega_{z}\left(t_{n}\right)\left(t_{n+1}-t_{n}\right)=\omega_{z}\left(t_{n}\right) \Delta t .
\end{aligned}
$$

It was considered that the acquired angular speed components are approximately constant during a sampling time period $\Delta t . \phi_{0}$ is the angular movement norm, and results with

$$
\phi_{0}\left(t_{n}\right)=\sqrt{\Delta \phi_{x}^{2}\left(t_{n}\right)+\Delta \phi_{y}^{2}\left(t_{n}\right)+\Delta \phi_{z}^{2}\left(t_{n}\right)} .
$$

Therefore, the new parameters of the attitude quaternion result under the form ([10], [12], [15]) 
"Mircea cel Batran" Naval Academy Scientific Bulletin, Volume XIX - 2016 - Issue 1

Published by "Mircea cel Batran" Naval Academy Press, Constanta, Romania // The journal is indexed in: PROQUEST / DOAJ / DRJI / JOURNAL INDEX / I2OR / SCIENCE LIBRARY INDEX / Google Scholar / Crossref /

Academic Keys / ROAD Open Access / OAJI / Academic Resources / Scientific Indexing Services / SCIPIO

$$
\begin{aligned}
q_{1}\left(t_{n+1}\right)= & C_{m} q_{1}\left(t_{n}\right)+S_{m} \Delta \phi_{z}\left(t_{n}\right) q_{2}\left(t_{n}\right)- \\
& -S_{m} \Delta \phi_{y}\left(t_{n}\right) q_{3}\left(t_{n}\right)+S_{m} \Delta \phi_{x}\left(t_{n}\right) q_{0}\left(t_{n}\right), \\
q_{2}\left(t_{n+1}\right)= & -S_{m} \Delta \phi_{z}\left(t_{n}\right) q_{1}\left(t_{n}\right)+C_{m} q_{2}\left(t_{n}\right)+ \\
& +S_{m} \Delta \phi_{x}\left(t_{n}\right) q_{3}\left(t_{n}\right)+S_{m} \Delta \phi_{y}\left(t_{n}\right) q_{0}\left(t_{n}\right), \\
q_{3}\left(t_{n+1}\right)= & S_{m} \Delta \phi_{y}\left(t_{n}\right) q_{1}\left(t_{n}\right)-S_{m} \Delta \phi_{x}\left(t_{n}\right) q_{2}\left(t_{n}\right)+ \\
& +C_{m} q_{3}\left(t_{n}\right)+S_{m} \Delta \phi_{z}\left(t_{n}\right) q_{0}\left(t_{n}\right), \\
q_{0}\left(t_{n+1}\right)= & -S_{m} \Delta \phi_{x}\left(t_{n}\right) q_{1}\left(t_{n}\right)-S_{m} \Delta \phi_{y}\left(t_{n}\right) q_{2}\left(t_{n}\right)- \\
& -S_{m} \Delta \phi_{z}\left(t_{n}\right) q_{3}\left(t_{n}\right)+C_{m} q_{0}\left(t_{n}\right) .
\end{aligned}
$$

According to the quaternion ortho-normalization procedure, we have the norm ([10], [12], [14], [15])

$$
\left|Q\left(t_{n+1}\right)\right|=\sqrt{q_{0}^{2}\left(t_{n+1}\right)+q_{1}^{2}\left(t_{n+1}\right)+q_{2}^{2}\left(t_{n+1}\right)+q_{3}^{2}\left(t_{n+1}\right)}
$$

and the new values for the quaternion parameters

$$
\begin{aligned}
& q_{1}\left(t_{n+1}\right)=\frac{q_{1}\left(t_{n+1}\right)}{\left|Q\left(t_{n+1}\right)\right|}, q_{2}\left(t_{n+1}\right)=\frac{q_{2}\left(t_{n+1}\right)}{\left|Q\left(t_{n+1}\right)\right|}, \\
& q_{3}\left(t_{n+1}\right)=\frac{q_{3}\left(t_{n+1}\right)}{\left|Q\left(t_{n+1}\right)\right|}, q_{0}\left(t_{n+1}\right)=\frac{q_{0}\left(t_{n+1}\right)}{\left|Q\left(t_{n+1}\right)\right|} .
\end{aligned}
$$

Based on the equivalence between the attitude quaternion and the attitude matrix it results

$$
\begin{aligned}
& r_{11}\left(t_{n+1}\right)=q_{0}^{2}\left(t_{n+1}\right)+q_{1}^{2}\left(t_{n+1}\right)-q_{2}^{2}\left(t_{n+1}\right)-q_{3}^{2}\left(t_{n+1}\right), \\
& r_{12}\left(t_{n+1}\right)=2\left[q_{1}\left(t_{n+1}\right) q_{2}\left(t_{n+1}\right)+q_{0}\left(t_{n+1}\right) q_{3}\left(t_{n+1}\right)\right], \\
& r_{13}\left(t_{n+1}\right)=2\left[q_{1}\left(t_{n+1}\right) q_{3}\left(t_{n+1}\right)-q_{0}\left(t_{n+1}\right) q_{2}\left(t_{n+1}\right)\right], \\
& r_{21}\left(t_{n+1}\right)=2\left[q_{1}\left(t_{n+1}\right) q_{2}\left(t_{n+1}\right)-q_{0}\left(t_{n+1}\right) q_{3}\left(t_{n+1}\right)\right], \\
& r_{22}\left(t_{n+1}\right)=q_{0}^{2}\left(t_{n+1}\right)+q_{2}^{2}\left(t_{n+1}\right)-q_{1}^{2}\left(t_{n+1}\right)-q_{3}^{2}\left(t_{n+1}\right), \\
& r_{23}\left(t_{n+1}\right)=2\left[q_{3}\left(t_{n+1}\right) q_{2}\left(t_{n+1}\right)+q_{0}\left(t_{n+1}\right) q_{1}\left(t_{n+1}\right)\right], \\
& r_{31}\left(t_{n+1}\right)=2\left[q_{1}\left(t_{n+1}\right) q_{3}\left(t_{n+1}\right)+q_{0}\left(t_{n+1}\right) q_{2}\left(t_{n+1}\right)\right], \\
& r_{32}\left(t_{n+1}\right)=2\left[q_{2}\left(t_{n+1}\right) q_{3}\left(t_{n+1}\right)-q_{0}\left(t_{n+1}\right) q_{1}\left(t_{n+1}\right)\right], \\
& r_{33}\left(t_{n+1}\right)=q_{0}^{2}\left(t_{n+1}\right)+q_{3}^{2}\left(t_{n+1}\right)-q_{1}^{2}\left(t_{n+1}\right)-q_{2}^{2}\left(t_{n+1}\right),
\end{aligned}
$$

where $r_{i j}$ are the attitude matrix elements. In the same time, the attitude matrix may be obtained by using three successive rotations (yaw angle $\psi$, pitch angle $\theta$, and roll angle $\varphi)([10]$, [12]-[15])

$$
\begin{aligned}
& r_{11}=\cos \theta \cos \psi, \\
& r_{12}=\cos \theta \sin \psi, \\
& r_{13}=-\sin \theta, \\
& r_{21}=\sin \varphi \sin \theta \cos \psi-\cos \varphi \sin \psi, \\
& r_{22}=\sin \varphi \sin \theta \sin \psi+\cos \varphi \cos \psi, \\
& r_{23}=\sin \varphi \cos \theta, \\
& r_{31}=\cos \varphi \sin \theta \cos \psi+\sin \varphi \sin \psi, \\
& r_{32}=\cos \varphi \sin \theta \sin \psi-\sin \varphi \cos \psi, \\
& r_{33}=\cos \varphi \cos \theta .
\end{aligned}
$$

As a consequence, knowing the values of the matrix elements at the current and previous times, by using the expressions (10) it results the attitude angles as follows

$$
\begin{aligned}
& \varphi=\operatorname{arctg}\left(r_{23} / r_{33}\right), \\
& \theta=\arcsin \left(-r_{13}\right), \\
& \psi=\operatorname{arctg}\left(r_{12} / r_{11}\right),
\end{aligned}
$$

equations which consider the trigonometric quadrants of the angles.

\section{Positioning algorithm}

Once converted into the NED frame, at the next step the acceleration components need to be corrected with the gravitational acceleration; as we already stated the accelerometers do not distinguish the kinematic acceleration $\vec{a}_{c}$ by the gravitational acceleration $\vec{g}$ and measure the resultant of the two

$$
\vec{a}=\vec{a}_{c}+\vec{g} .
$$

Therefore, it is necessary to use a model for the Earth gravitational field to can perform the necessary corrections. According to [10] and [15], the components of gravitational acceleration in NED frame are given by the next equations

$$
\begin{aligned}
& g_{x l} \cong 0, \\
& g_{y l} \cong 0, \\
& g_{z l} \cong 9,7803+0,0519 \cdot \sin ^{2} \phi-3,086 \cdot 10^{-6} \cdot h,
\end{aligned}
$$

where $\varphi$ is the geodetic latitude and $h$ is the vehicle altitude. From this point two successive numerical integration steps are performed in order to establish the components of speed and vehicle position in NED frame.

The global positioning of the vehicle (calculus of its geodetic coordinates) will be made through the conversion of its NED coordinates in ECEF and at the end in SG frame. Because for our navigation problem the NED frame was considered fixed relative to the Earth surface, these conversions will be made without considering Poisson equations (the latitude and longitude variation are very small for our applications).

Because in our case the transformation $\mathrm{NED} \rightarrow \mathrm{ECEF}$ is used to convert the coordinates of a point and the two frames have different origins, we need to considers the transformation composed by a translation and a rotation,

$$
\left[\begin{array}{l}
x_{P} \\
y_{P} \\
z_{P}
\end{array}\right]=\left[\begin{array}{l}
x_{O^{\prime}} \\
y_{O^{\prime}} \\
z_{O^{\prime}}
\end{array}\right]+R_{I}^{P}\left[\begin{array}{l}
x_{I} \\
y_{I} \\
z_{l}
\end{array}\right] .
$$

$\left(x_{P}, y_{P}, z_{P}\right)$ and $\left(x_{O^{\prime}}, y_{O^{\prime}}, z_{O^{\prime}}\right)$ are the coordinates of the vehicle and of the origin $\mathrm{O}^{\prime}$ of the NED frame in ECEF frame, $\left(x_{l}, y_{l}, z_{l}\right)$ are the coordinates of the vehicle in the NED frame, and $R_{I}^{P}$ is the 
"Mircea cel Batran" Naval Academy Scientific Bulletin, Volume XIX - 2016 - Issue 1

Published by "Mircea cel Batran" Naval Academy Press, Constanta, Romania // The journal is indexed in:

PROQUEST / DOAJ / DRJI / JOURNAL INDEX / I2OR / SCIENCE LIBRARY INDEX / Google Scholar / Crossref /

Academic Keys I ROAD Open Access / OAJI / Academic Resources / Scientific Indexing Services / SCIPIO

rotation matrix NED $\rightarrow$ ECEF ([10], [12])

$$
R_{I}^{P}=\left[\begin{array}{ccc}
-\sin \phi \cdot \cos \lambda & -\sin \lambda & -\cos \phi \cdot \cos \lambda \\
-\sin \phi \cdot \sin \lambda & \cos \lambda & -\cos \phi \cdot \sin \lambda \\
\cos \phi & 0 & -\sin \phi
\end{array}\right]
$$

So, the vehicle coordinates in ECEF result with equation

$$
\left[\begin{array}{l}
x_{P} \\
y_{P} \\
z_{P}
\end{array}\right]=\left[\begin{array}{l}
x_{O^{\prime}} \\
y_{O^{\prime}} \\
z_{O^{\prime}}
\end{array}\right]+\left[\begin{array}{ccc}
-\sin \phi \cdot \cos \lambda & -\sin \lambda & -\cos \phi \cdot \cos \lambda \\
-\sin \phi \cdot \sin \lambda & \cos \lambda & -\cos \phi \cdot \sin \lambda \\
\cos \phi & 0 & -\sin \phi
\end{array}\right]\left[\begin{array}{l}
x_{I} \\
y_{I} \\
z_{l}
\end{array}\right]
$$

As can be observed, the NED $\rightarrow$ ECEF transformation needs an initialization step, i.e. to know the coordinates of NED frame origin $\mathrm{O}^{\prime}$ in ECEF frame $\left(x_{O^{\prime}}, y_{O^{\prime}}, z_{O^{\prime}}\right)$; this calculation will be highlighted in the next steps, depending by the initial values of the vehicle latitude and longitude.

The transformation which complete the vehicle positioning is performed between ECEF and SG frames. In this situation, the geodetic coordinates of the vehicle, $\lambda, \quad$ qeeadth, be expressed as functions of its rectangular coordinates $x_{P}, y_{P}$ and $z_{P}$. Because the Earth surface is approximated with an ellipsoid, the local vertical don't passes through its centrum (Fig. 4); $N$ - the local vertical, a - semi major axis of the geodetic ellipse $(a=6378137.0 \mathrm{~m}), b$ - semi minor axis of the geodetic ellipse $(b=6356752.3142 \mathrm{~m})$. The obtained values for flattening and eccentricity are

$$
\begin{aligned}
& f=\frac{a-b}{a}=0.0034, \\
& e=\sqrt{f(2-f)}=0.0818,
\end{aligned}
$$

their allowing the calculus of $N$ as a function of latitude $\varphi$ as follows

$$
N(\phi)=\frac{a}{\sqrt{1-e^{2} \sin ^{2}(\phi)}} .
$$

According to Fig. 4, the coordinates $x_{P}, y_{P}, z_{P}$ calculation starting from the geodetic coordinates $\lambda, \quad$ (pramsdimation $S G \rightarrow E C E F$ ) is made by using the next equations

$$
\begin{aligned}
& x_{P}=(N+h) \cos \phi \cos \lambda, \\
& y_{P}=(N+h) \cos \phi \sin \lambda, \\
& z_{P}=\left[N\left(1-e^{2}\right)+h\right] \sin \phi .
\end{aligned}
$$

Starting from these equations it result the equation which perform the inverse transformation. Combining the first two equations it is obtained

$$
\lambda=\operatorname{arctg}\left(y_{P} / x_{P}\right) \text {. }
$$

The calculus of latitude and altitude is a little bit complicated, requiring an iterative algorithm ([10]): I. Initialization

$$
h=0, N=a, p=\sqrt{x_{P}^{2}+y_{P}^{2}} .
$$

II. Performing the next iteration until convergence

$$
\begin{gathered}
\sin \phi=\frac{z_{P}}{N\left(1-e^{2}\right)+h}, \\
\phi=\operatorname{arctg}\left[\left(z_{P}+e^{2} N \sin \phi\right) / p\right],
\end{gathered}
$$

$$
N(\phi)=\frac{a}{\sqrt{1-e^{2} \sin ^{2} \phi}},
$$

$$
h=\frac{p}{\cos \phi}-N
$$

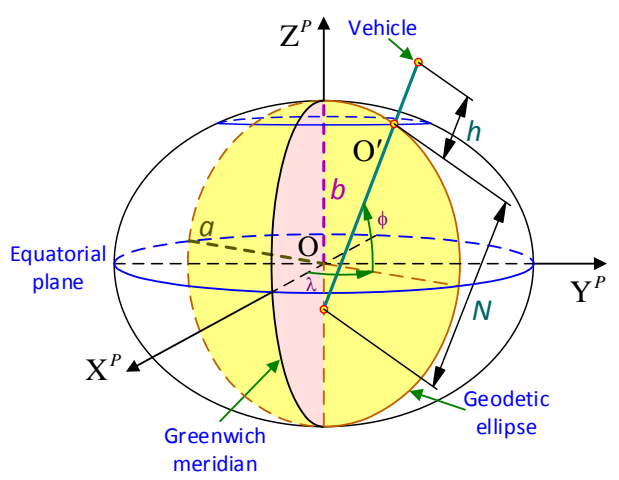

Fig. $4 \mathrm{SG} \rightarrow$ ECEF transformation

To determine the coordinates of NED frame origin $O^{\prime}$ in ECEF frame $\left(x_{O^{\prime}}, y_{O^{\prime}}, z_{O^{\prime}}\right)$ the initial values of the vehicle global coordinates, $\lambda_{0}$ and $\wp$ are used. It results

$$
\begin{gathered}
N_{0}=N\left(\phi_{0}\right)=\frac{a}{\sqrt{1-e^{2} \sin ^{2}\left(\phi_{0}\right)}}, \\
x_{O^{\prime}}=N_{0} \cos \phi_{0} \cos \lambda_{0}, \\
y_{O^{\prime}}=N_{0} \cos \phi_{0} \sin \lambda_{0}, \\
z_{O^{\prime}}=N_{0}\left(1-e^{2}\right) \sin \phi_{0} .
\end{gathered}
$$

These equations complete the model (16) providing the NED $\rightarrow$ ECEF conversion.

Considering that the take-off for our monitored vehicle is made at an altitude $h_{0}$ (or the flight data analysis starting at $h_{0}$ altitude), then, to avoid iterations in a step time, the algorithm for the vehicle global positioning may be reorganised under the net form.

I. Initialization $\left(t_{0}\right)$ :

$$
h=h_{0}, N=N\left(\phi_{0}\right)=N_{0}, \lambda=\lambda_{0}, \phi=\phi_{0} .
$$


"Mircea cel Batran" Naval Academy Scientific Bulletin, Volume XIX - 2016 - Issue 1

Published by "Mircea cel Batran" Naval Academy Press, Constanta, Romania // The journal is indexed in: PROQUEST / DOAJ / DRJI / JOURNAL INDEX / I2OR / SCIENCE LIBRARY INDEX / Google Scholar / Crossref /

Academic Keys I ROAD Open Access / OAJI / Academic Resources / Scientific Indexing Services / SCIPIO

II. $n\left(t_{n}\right)$ calculation step:

$$
\begin{gathered}
h=h\left(t_{n-1}\right), \\
N=N\left(\phi\left(t_{n-1}\right)\right)=\frac{a}{\sqrt{1-e^{2} \sin ^{2}\left[\phi\left(t_{n-1}\right)\right]}}, \\
p\left(t_{n}\right)=\sqrt{x_{P}^{2}\left(t_{n}\right)+y_{P}^{2}\left(t_{n}\right)}, \\
\lambda\left(t_{n}\right)=\operatorname{arctg}\left[y_{P}\left(t_{n}\right) / x_{P}\left(t_{n}\right)\right], \\
\sin \phi=\frac{z_{P}\left(t_{n}\right)}{N\left(1-e^{2}\right)+h}, \\
N\left(t_{n}\right)=\operatorname{arctg}\left[\left(z_{P}\left(t_{n}\right)+e^{2} N \sin _{n}\right) / p\left(t_{n}\right)\right], \\
N\left(\phi\left(t_{n}\right)\right)=\frac{a}{\sqrt{1-e^{2} \sin ^{2} \phi\left(t_{n}\right)}}, \\
h\left(t_{n}\right)=\frac{p\left(t_{n}\right)}{\cos \phi\left(t_{n}\right)}-N\left(t_{n}\right) .
\end{gathered}
$$

Actually, the determination of the current latitude $\phi\left(t_{n}\right)$ is made by using the values of $h$ and $N$ from the previous step $\left(t_{n-1}\right)$. The approximation is a good one, having in mind the very small variation of these parameters during a step time.

\section{Software implementation and evaluation}

For the attitude algorithm were built Matlab/Simulink multilayer blocks, accessed by the user based on S-functions implementing the mathematical models. The block from layer 1 (Fig. 5 [12]), "Attitude", has as inputs the angular speed readings $\left(\omega_{x v}, \omega_{y v}, \omega_{z v}\right)$ provided by the gyros and expressed in degrees/s, and as outputs the rotation matrix (DCM) NED $\rightarrow \mathrm{SV}\left(R_{l}^{v}\right)$ and attitude angles $(\varphi, \theta, \psi)$ expressed in degrees. At the level of the second layer (Fig. 6 [12]), there are two blocks: 1) „Attitude L2”, which implements an Sfunction and 2) "Rotation Angles to DCM”, which implements the equations (10) calculating the elements of the $R_{l}^{v}$ matrix starting from the attitude angles values.

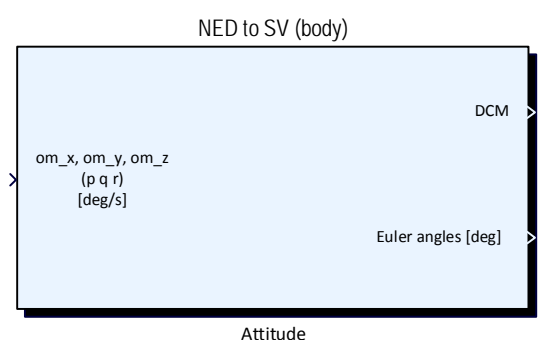

Fig. 5 „Attitude” block providing the NED $\rightarrow$ SV rotation matrix and attitude angles
For the „Attitude” block was realised an interface which allows user to set the sample time and the initial values of the attitude angles.

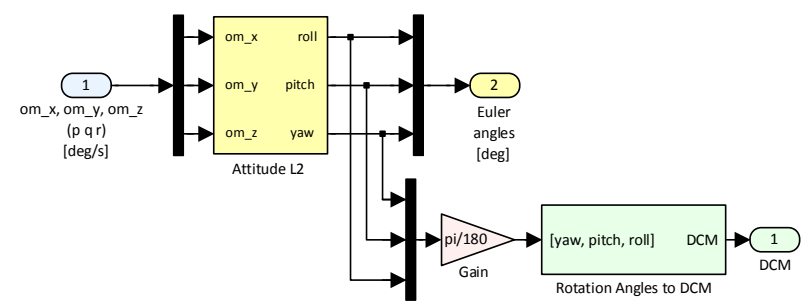

Fig. 6 The second layer of the „Attitude” block

At the next step the $R_{I}^{v}$ matrix is transposed and the result is multiplied with the acceleration components in SV. The associated block for these operations are already implemented in the Matlab/Simulink library. The determination of the position in NED is realised through the numerical integration of the vehicle kinematic acceleration $\vec{a}_{c}$ components $\left(a_{N}, a_{E}, a_{D}\right)$ in NED, obtained through the correction of the linear acceleration $\vec{a}$ components $\left(a_{x l}, a_{y l}, a_{z l}\right)$ with the gravitational acceleration $\vec{g}\left(g_{x l}, g_{y l}, g_{z l}\right)$,

$$
\begin{aligned}
& a_{N}=a_{x l}+g_{x l}, \\
& a_{E}=a_{y l}+g_{y l}, \\
& a_{D}=a_{z l}+g_{z l} .
\end{aligned}
$$

For this numerical integration was realised the Matlab/Simulink block „accNED_posNED” (Fig. 7). An interface was implemented for this block, allowing the user to set the Sample time and the initial values of the speed and altitude (Initial $\mathrm{N}$ speed, Initial E speed, Initial D speed, Initial altitude). The initial positions on North and East are considered to be zero because NED was considered to be fixed relative to the Earth surface, while the initial position on Down axis equals $-h$. The inputs of the „accNED_posNED” block are the acceleration components in NED $\left(a_{N}, a_{E}, a_{D}\right)$, expressed in $\mathrm{m} / \mathrm{s}^{2}$, while the outputs are the speed components in NED $\left(v_{N}, v_{E}, v_{D}\right)$, expressed in $\mathrm{m} / \mathrm{s}$, and the vehicle coordinates in NED $\left(x_{l}, y_{l}, z_{l}\right)$, expressed in $\mathrm{m}$. 
"Mircea cel Batran" Naval Academy Scientific Bulletin, Volume XIX - 2016 - Issue 1

Published by "Mircea cel Batran" Naval Academy Press, Constanta, Romania // The journal is indexed in: PROQUEST / DOAJ / DRJI / JOURNAL INDEX / I2OR / SCIENCE LIBRARY INDEX / Google Scholar / Crossref / Academic Keys I ROAD Open Access / OAJI / Academic Resources / Scientific Indexing Services / SCIPIO

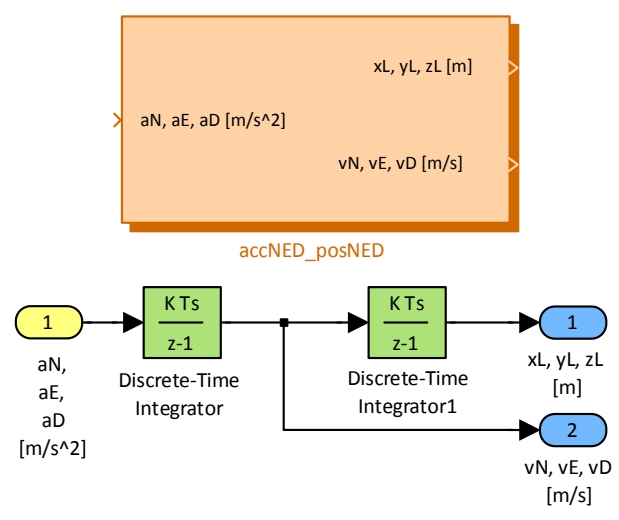

Fig. 7 „accNED_posNED” block

The conversion of the position from NED to SG cam be performed directly, or in two successive steps, with an intermediary passing through ECEF frame. For the direct transition from NED to SG are combined the mathematical models obtained for the transitions NED $\rightarrow E C E F$ and ECEF $\rightarrow$ SG in a single S-function, the necessary feedback after the initial longitude and latitude (see initialisation of the $O$ ' position in ECEF) being performed in the code of S-function. The obtained block, "NED to SG”, is shown in Fig. 8; it has as inputs the coordinates of the vehicle in NED frame (expressed in $m$ ), and as outputs the global coordinates of the vehicle, latitude and longitude (expressed in degrees), and altitude (expressed in $\mathrm{m}$ ). The implemented interface for this block allows the user to set the initial values of the global coordinates, initial latitude and initial longitude (expressed in degrees), and initial altitude (expressed in $\mathrm{m}$ ).

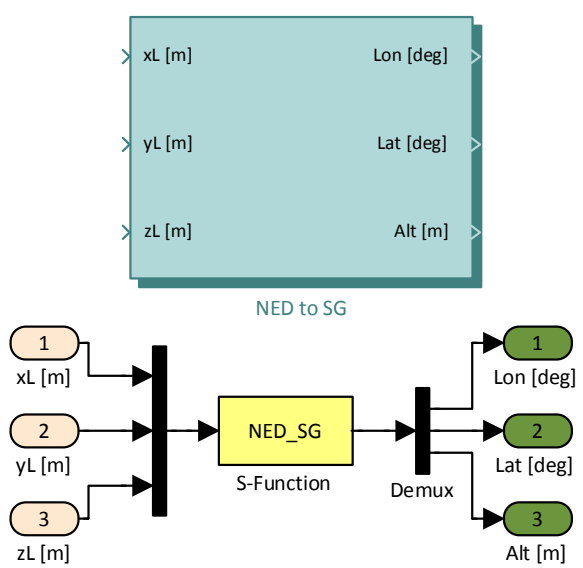

Fig. 8 "NED to SG" block

The closing of the algorithm in the navigator is performed through the software implementation of the Earth gravitational model described by equations (13). The obtained model is the Matlab/Simulink block "gNED” shown in Fig. 9. Its inputs are the geodetic latitude (expressed in degrees), and the altitude (expressed in $\mathrm{m}$ ), while its outputs are the components of the gravitational acceleration in NED frame (expressed in $\mathrm{m} / \mathrm{s}^{2}$ ). The "gDown" function implements the third equation (13).

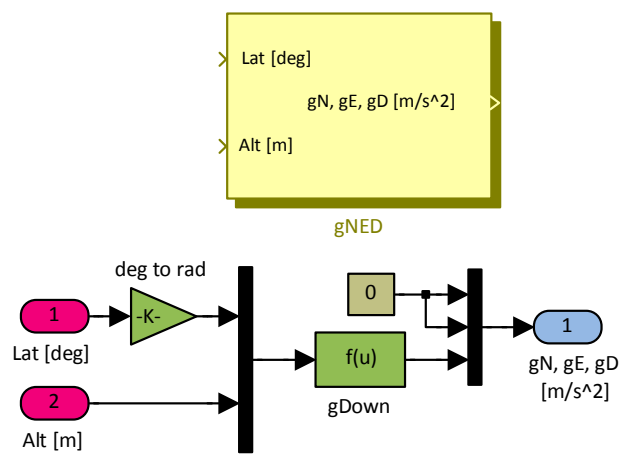

Fig. 9 Gravitational model "gNED"

By integrating the developed Matlab/Simulink models for various parts of the navigation algorithm, it is obtained the navigator model in Fig. 10. 
"Mircea cel Batran" Naval Academy Scientific Bulletin, Volume XIX - 2016 - Issue 1

Published by "Mircea cel Batran" Naval Academy Press, Constanta, Romania // The journal is indexed in: PROQUEST / DOAJ / DRJI / JOURNAL INDEX / I2OR / SCIENCE LIBRARY INDEX / Google Scholar / Crossref /

Academic Keys I ROAD Open Access / OAJI / Academic Resources / Scientific Indexing Services / SCIPIO

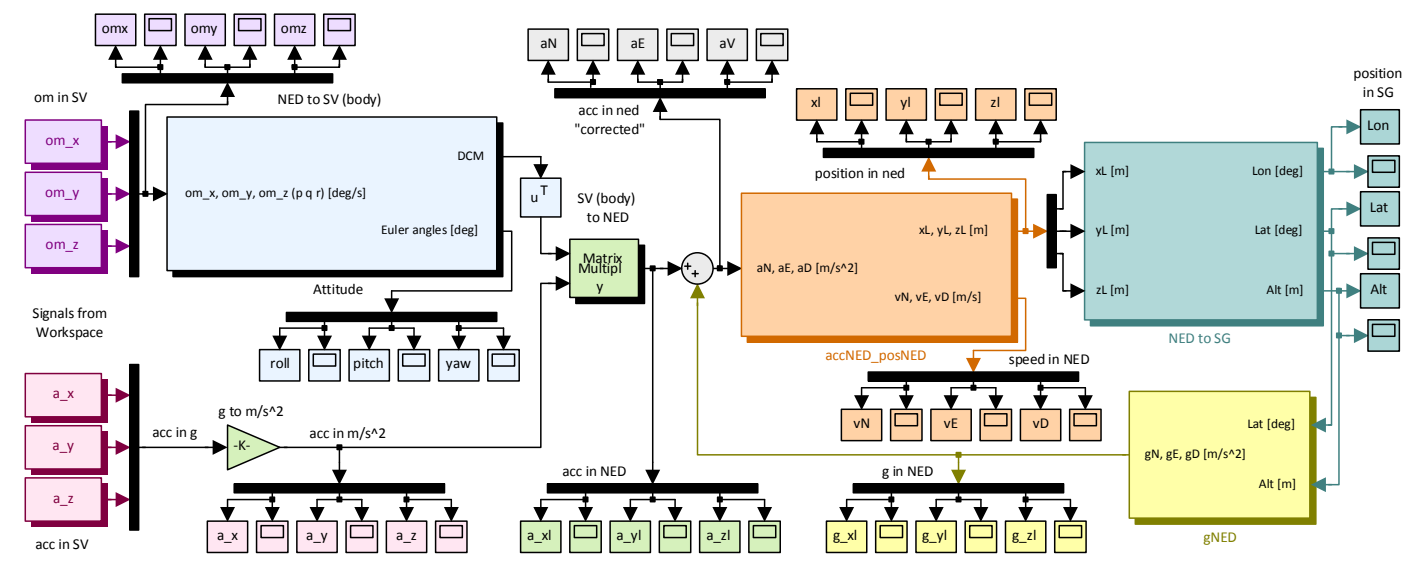

Fig. 10 Matlab/Simulink model of the strap-down inertial navigator

Evaluating the obtained software structure for the inflight acquired data shown in Fig. 11 for gyros readings and in Fig. 12 for accelerometers readings, were obtained the solutions presented in Fig. 13 for attitude angles (roll, pitch and yaw), in Fig. 14 for speed components in NED (North, East and Vertical speeds), and in Fig. 15 for global positioning of the vehicle (longitude, latitude and altitude).

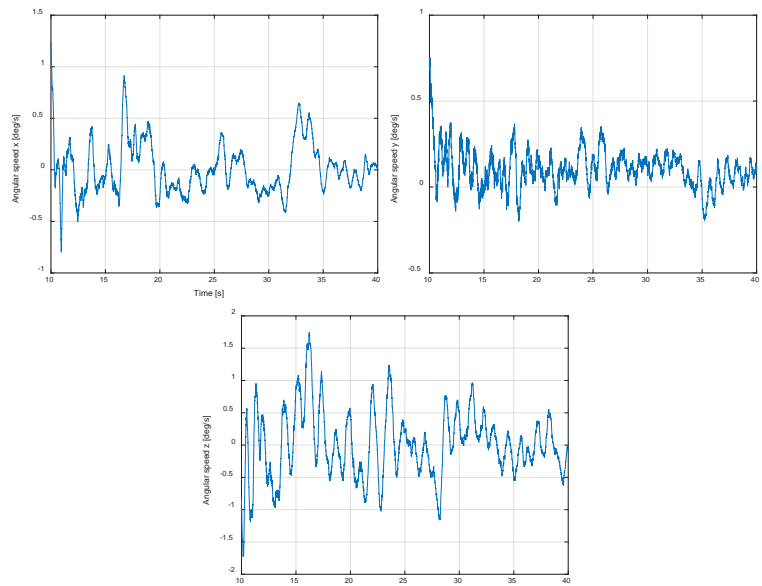

Fig. 11 Gyros readings

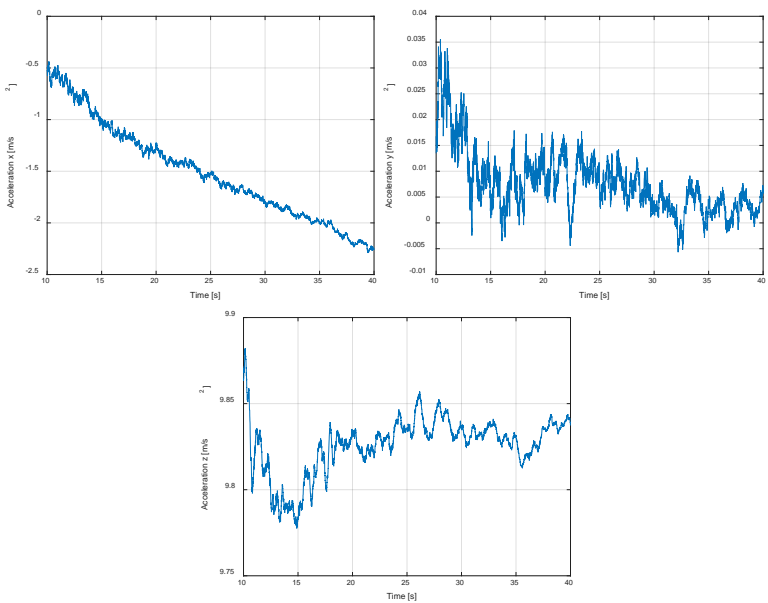

Fig. 12 Accelerometers readings

DOI: 10.21279/1454-864X-16-I1-040

(c) 2015. This work is licensed under the Creative Commons Attribution-Noncommercial-Share Alike 4.0 License.
All tests performed with the developed structure, both at the lab level but also using flight test data, proved its good functioning and guaranteed that it can be used in the actual form in the debriefing process after the flight tests.
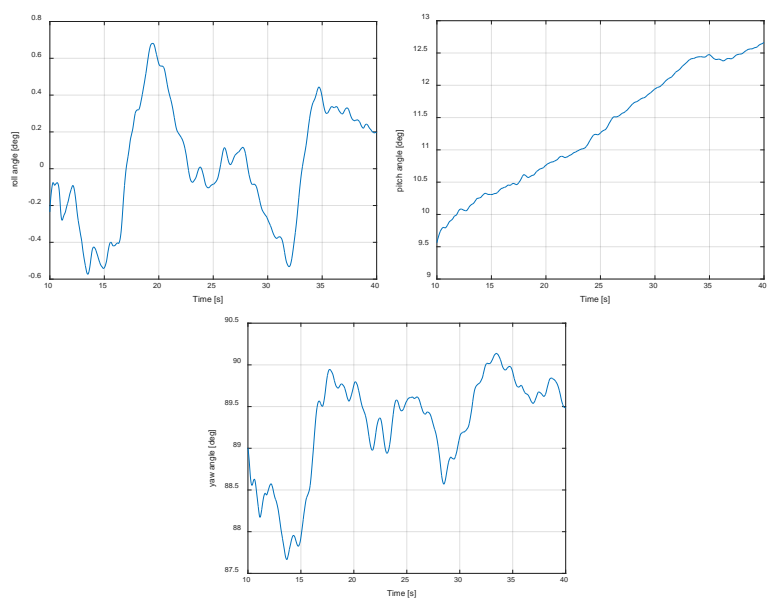

Fig. 13 Attitude angles

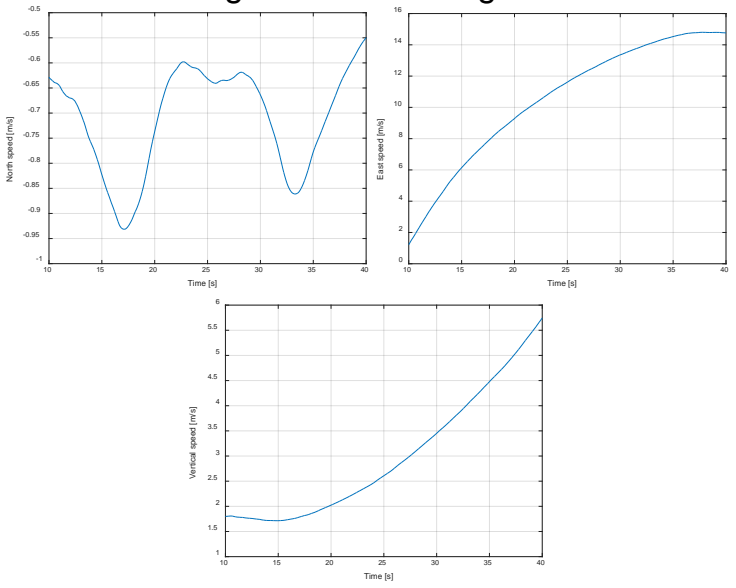

Fig. 14 Speed components in NED 
"Mircea cel Batran" Naval Academy Scientific Bulletin, Volume XIX - 2016 - Issue 1

Published by "Mircea cel Batran" Naval Academy Press, Constanta, Romania /I The journal is indexed in: PROQUEST / DOAJ / DRJI / JOURNAL INDEX / I2OR / SCIENCE LIBRARY INDEX / Google Scholar / Crossref /

Academic Keys I ROAD Open Access / OAJI / Academic Resources / Scientific Indexing Services / SCIPIO

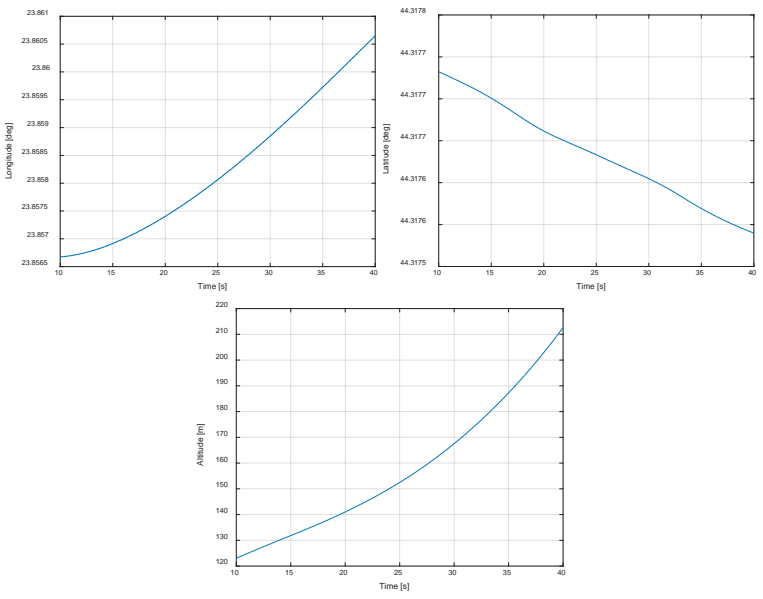

Fig. 15 Global positioning of the vehicle

\section{CONCLUSIONS}

The paper presented the mathematical modelling and software implementation of a strap-down inertial navigation algorithm used for an Unmanned Aerial Vehicle (UAV) boarding an optical detection system for the detection of the Corona discharge in high voltage power lines.

The developed algorithm may be used both on real time positioning, but also in the debriefing process after the flight test. The evaluation of the software structure, both at the lab level through numerical simulation, but also by using flight test data, proved its good functioning and confirms the possibility to be used in another configuration in the Ground Mission Analysis System (GMAS).

\section{BIBLIOGRAPHY}

[1] Popovici, D., Lolea, M., High Voltage Technique, University of Oradea, 2011

[2] Mayerhoff, E., Corona and its Effects, High Voltage Connection Inc.,

http://www.highvoltageconnection.com/articles/corona.pdf

[3] Sharma, S., Goel, K., Gupta, A., Kumar, H., Corona effects on EHV AC transmission lines, International Journal of Scientific Research Engineering \& Technology (IJSRET), Vol. 1(5), pp. 160-164, 2012

[4] Ma, L., Chen, Y.Q. Aerial Surveillance System for Overhead Power Line Inspection, Technical Report No. USU-CSOIS-TR-04-08, Center for Self-Organizing and Intelligent Systems (CSOIS), Department of Electrical and Computer Engineering, College of Engineering, Utah State University, USA, 2004, http://mechatronics.ece.usu.edu/reports/

[5] Barbour, N., Hopkins, R., Kourepenis, A., Ward, P., Inertial MEMS System Applications, RTO-EN-SET 116, Low-Cost Navigation Sensors and Integration Technology, March, 2011.

[6] Bekir, E., Introduction to Modern Navigation Systems, World Scientific Publishing, 2007.

[7] Titterton, D.H., Weston, J., Strapdown inertial navigation technology - 2nd Edition. Institution of

Engineering and Technology, 2004.

[8] Grigorie, T.L., Edu, I.R., Inertial navigation applications with miniaturized sensors. SITECH, Craiova, Romania, 2013.

[9] Schmidt, G., INS/GPS Technology Trends. RTO-EN-SET-116, Low-Cost Navigation Sensors and Integration Technology, March 2011

[10] Farrell, J., Aided Navigation. GPS with High Rate Sensors. McGraw-Hill, 2008.

[11] Grewal, M.S., Andrews, A.P., Bartone, C.G., Global Navigation Satellite Systems, Inertial Navigation, and Integration, 3rd Edition, John Wiley \& Sons, 2013.

[12] Grigorie, T.L., Sandu, D.G., Navigation systems synergic architectures with strap-down inertial components. SITECH, Craiova, Romania, 2013.

[13] Grigorie, T.L., Strap-Down Inertial Navigation Systems. Optimization studies. SITECH, Craiova, Romania, 2007.

[14] Salychev, O.S. Inertial Systems in Navigation and Geophysics. Bauman MSTU Press, Moscow, 1998, 360p, ISBN 5-7038-1346-8.

[15] Radix, J.C. Systemes inertiels a composants lies $<<$ Strap-Down $>>$, Cepadues-Editions, Ecole Nationale Superieure de l'Aeronautique et de l'Espace SUP'AERO, Toulouse, 1993 